\title{
Determination of Vitamins $D_{2}$ and $D_{3}$ in Edible Fungus by Reversed-Phase Two-Dimensional Liquid Chromatography
}

\author{
Bai-Fen Huang, Xiao-Dong Pan, Jing-Shun Zhang, Jiao-Jiao Xu, and Zeng-Xuan Cai \\ Zhejiang Provincial Center for Disease Control and Prevention, Hangzhou, China \\ Correspondence should be addressed to Zeng-Xuan Cai; caizx_cdc@163.com
}

Received 23 July 2020; Revised 19 August 2020; Accepted 10 September 2020; Published 22 September 2020

Academic Editor: Fatma M. El-Demerdash

Copyright ( $\odot 2020$ Bai-Fen Huang et al. This is an open access article distributed under the Creative Commons Attribution License, which permits unrestricted use, distribution, and reproduction in any medium, provided the original work is properly cited.

\begin{abstract}
Vitamin D is the name given to a series of compounds with antirachitic activity. In this study, we developed a method for quantification of the common Vitamin D, ergocalciferol (vitamin $\mathrm{D}_{2}$ ), and cholecalciferol (vitamin $\mathrm{D}_{3}$ ), in edible fungus by reversed-phase two-dimensional liquid chromatography. The sample was saponified by $\mathrm{KOH}$ ethanol solution and extracted with ethyl acetate and $n$-hexane. After reconcentration, the sample was directly injected for instrumental analysis. The results showed that the spiking recoveries of vitamin $\mathrm{D}_{2}$ and vitamin $\mathrm{D}_{3}$ were $80.4-93.8 \%$ and $82.3-92.0 \%$, respectively. The relative standard deviations (RSDs) were all less than 5\%. Comparing to the results of isotope dilution liquid chromatography tandem mass spectrometry, there were no significant differences $(P>0.05)$. The method was applied for testing vitamin $\mathrm{D}_{2}$ and $\mathrm{D}_{3}$ in 9 kinds of edible mushrooms. It showed that vitamin $\mathrm{D}_{3}$ was not detected. The content of vitamin $\mathrm{D}_{2}$ ranged from $0.11 \mu \mathrm{g} / 100 \mathrm{~g}$ to $123 \mu \mathrm{g} / 100 \mathrm{~g}$. The content of vitamin $\mathrm{D}_{2}$ in dried mushroom was the highest, while that in fresh mushroom was the lowest. The limit of quantification was $0.025 \mu \mathrm{g} / 100 \mathrm{~g}$.
\end{abstract}

\section{Introduction}

Vitamin D (VD), fat soluble vitamin, is a type of steroid derivatives. Among them, ergosterol (vitamin $\mathrm{D}_{2}, \mathrm{VD}_{2}$ ) and cholecalciferol (vitamin $\mathrm{D}_{3}, \mathrm{VD}_{3}$ ) [1] are the most important to human body. Vitamin $\mathrm{D}_{2}$ is made from ergosterol in plants or yeast by ultraviolet irradiation, also known as solar vitamin $[2,3]$. Vitamin $\mathrm{D}_{3}$ is made of 7-dehydrocholesterol under human skin by ultraviolet irradiation. The structure of vitamin $\mathrm{D}_{2}$ is very similar and has the same biological activity. Vitamin D is essential to maintain the normal physiological function of the body. Although the skin can synthesize a small amount of vitamin $\mathrm{D}$ when exposed to the sun, the amount of vitamin D synthesized is fluctuant, and long-term ultraviolet radiation will increase the risk of skin cancer [4]. Therefore, the human body generally needs to take vitamin D through diet. Dried Lentinus edodes or edible mushrooms irradiated by ultraviolet rays are also good sources of vitamin D dietary intake.

At present, high-performance liquid chromatography (HPLC) [5-15] and liquid chromatography tandem mass spectrometry (LC-MS/MS) [16-23] are commonly used to detect vitamin D in food. HPLC usually adopts two-phase liquid chromatography [5-10]. Firstly, VD is separated from impurities in normal phase chromatography system, and VD fraction is collected by fraction collector. Then, normalphase solvent in collected liquid is removed by evaporation, and vitamins $\mathrm{D}_{2}$ and $\mathrm{D}_{3}$ are separated and determined in the reversed-phase chromatography system. However, the above method has disadvantages of tedious analysis steps, low detection sensitivity, and large repeatability deviation.

It has been reported that vitamin $\mathrm{D}_{2}$ in Lentinus edodes or Agaricus bisporus after UV irradiation was determined by the RP-HPLC-UV detection method [12]. But, the detection sensitivity of this method cannot meet the requirements of fresh edible fungi cultivated in conventional growth environment. Although LC-MS/MS with good selectivity and high sensitivity can simultaneously detect vitamin $\mathrm{D}_{2}$ and $\mathrm{D}_{3}$, the test cost of instrument and special stable isotopeinternal standards should be considered. With the development of two-dimensional chromatography technology, online two-dimensional chromatography method for the 
determination of nutrients in infant formula food and adult nutrition products has been reported [24-26].

In this study, we aimed to develop a method for the determination of vitamin $\mathrm{D}_{2}$ and $\mathrm{D}_{3}$ in edible fungi and their products by two-dimensional reversed-phase liquid chromatography. The content of vitamin $\mathrm{D}_{2}$ and vitamin $\mathrm{D}_{3}$ in 9 kinds of edible fungi were determined by this method. It was found that there was difference of vitamin D contents among different varieties, growing environment, and drying processes.

\section{Materials and Methods}

2.1. Chemical Reagents. HPLC grade of methanol (MEOH), acetonitrile $(\mathrm{ACN})$, and ethanol $(\mathrm{EOH})$ were purchased from fisher chemical (Product of Canada). Analytical grade $n$-hexane, isooctane, ethyl acetate, petroleum ether $\left(30-60^{\circ} \mathrm{C}\right)$, potassium hydroxide, L-ascorbic acid, and 2,6ditert-butyl para-cresol were purchased from Shanghai Linfeng Chemical Reagent Co. Ltd (China). Ultrapure water was obtained from a Milli-Q water purification system (Millipore, USA). Vitamin $\mathrm{D}_{2}$ and $\mathrm{D}_{3}$ were purchased from Dr. Ehrenstorfor GmbH. Edible mushrooms were purchased from local supermarkets in Hangzhou, China.

2.2. Analytical Instrumentation. The 2D-LC system was composed of one dimension for Agilent 1260 Infinity Quaternary Pump (G1311B), Agilent 1260 Infinity Autosampler (G1329B), Agilent 1260 Infinity Thermostatted Column Compartment (G1316A) with built-in 2-position/6port valve, Agilent 1260 Infinity UV Detector (G1314), second dimension for Agilent 1260 Infinity Degasser (G1322A), Agilent 1260 Infinity Binary Pump (G1312B), and Agilent 1260 Infinity Diode Array Detector (G4212B) equipped with $60 \mathrm{~mm}$ ultrasensitive flow cell.

The first phase was the sample injection step, and VD was captured online in a column cartridge right after it was eluted from the first column, with the valve switched to positions 1-6. In the third phase, with the valve switched back to positions 1-2, the second dimension was undergoing the separation and detection of VD. The specific details are shown in Table 1. In this method, a high-efficiency column (Daicel Corporation Chiralcel ${ }^{\mathrm{R}}$ OD-3R, $2.1 \mathrm{~mm} \times 150 \mathrm{~mm}$, $3 \mu \mathrm{m}$ ) was used in the first dimension for $\mathrm{VD}$, and its precursors were separated from other impurities. An Agilent ZORBAX Eclipse PAH $(4.6 \times 100 \mathrm{~mm}, 3.5 \mu \mathrm{m})$ column in the second dimension improved the separation of $\mathrm{VD}_{2}$ and $\mathrm{VD}_{3}$. Meanwhile, the two-dimension DAD detector was equipped with an ultrasensitive flow cell $(60-\mathrm{mm}$ path length) to improve the sensitivity.

2.3. Preparation of Standard Solutions. $1.0 \mathrm{mg} / \mathrm{mL}$ of vitamins $\mathrm{D}_{2}$ and $\mathrm{D}_{3}$ standard stock solution was prepared in anhydrous alcohol and stored in brown glass bottle at $-20^{\circ} \mathrm{C}$. Their concentrations were evaluated spectrophotometrically based on their specific absorption coefficients: vitamin $\mathrm{D}_{2}=461$ at $265 \mathrm{~nm}$; vitamin $\mathrm{D}_{3}=485$ at $265 \mathrm{~nm} .10 \mu \mathrm{g} / \mathrm{mL}$ mixed standard solution was prepared by $1 \mathrm{~mL}$ of each stock standard solutions to $100 \mathrm{~mL}$ volumetric flask and then the volumetric flasks were filled up with methanol. Working solutions were prepared by methanol/water (80/20) in appropriate dilution times.

2.4. Sample Collection and Preparation. Samples of edible mushrooms were taken from three supermarkets in Hangzhou, and the samples of the same variety from three supermarkets were then mixed. A flow chart of the sample preparation procedure is presented in Figure 1. For the first step, sample saponification extraction, homogenized sample $1.0 \mathrm{~g}$ (dry sample) or $5.0 \mathrm{~g}$ (wet sample) was transferred to a screw-top centrifuge tube, with $0.2 \mathrm{~g}$ ascorbic acid, ultrapure water was added to $10 \mathrm{~mL}$, and the sealed tube was agitated thoroughly. To this mixture, $12 \mathrm{~mL}$ ethanol containing $0.2 \%$ butylated hydroxytoluene (BHT) and $6 \mathrm{~mL} 50 \%$ potassium hydroxide anhydrous ether were added, and the sealed tube was vortexed for 16 hours by multifunctional scroll oscillator at $1500 \mathrm{r} / \mathrm{min}$. Finally, $20 \mathrm{~mL} \times 2 n$-hexane/ethyl acetate (4/ 6 ) was added, and the sealed tube was vortexed for $10 \mathrm{~min}$. The sealed $50 \mathrm{~mL}$ tube was centrifuged at $8000 \mathrm{r} / \mathrm{min}$ for $5 \mathrm{~min}$, the organic layer (top) was collected to another $50 \mathrm{~mL}$ tube, ultrapure water was added to $50 \mathrm{~mL}$, the sealed tube was vortexed for $1 \mathrm{~min}$, centrifuged at $8000 \mathrm{r} / \mathrm{min}$ for $5 \mathrm{~min}$, upper volume was recorded, then $10 \mathrm{~mL}$ organic layer (top) was quantitatively transferred to $10 \mathrm{~mL}$ graduated test tube with stopper, condensed by a flowing stream of $N_{2}$ while the sample was heated at $40^{\circ} \mathrm{C}$ in a water bath, the residue was taken up in $4 \mathrm{~mL}$ methanol, and the sealed tube was vortexed for $3 \mathrm{~min}$, then ultrapure water was added to $5 \mathrm{~mL}$ scale line, and the sealed tube was vortexed for $1 \mathrm{~min}$, centrifuged at $8000 \mathrm{r} / \mathrm{min}$ for $5 \mathrm{~min}$, and the lotions were filtered and injected into the HPLC column. All measurements were performed in triplicate by using one sample. The results of all measurements are expressed as mean \pm SD.

2.5. Quantification and Method Validation. To ensure the absence of contamination of solvents and cartridges, a blank sample without sample matrix was carried out according to the procedures in Table 1. There is no quality control substance for vitamin $\mathrm{D}_{2}$ and $\mathrm{D}_{3}$ of edible mushrooms. Accordingly, three concentrations of vitamins $\mathrm{D}_{2}$ and $\mathrm{D}_{3}$ $(50 \mu \mathrm{g} / 100 \mathrm{~g}, 100 \mu \mathrm{g} / 100 \mathrm{~g}$, and $200 \mu \mathrm{g} / 100 \mathrm{~g})$ were spiked into the dried mushroom powder for the recovery test $(n=6)$ to verify the accuracy of the developed method. The relative standard deviations of test results were used for precision evaluation.

\section{Results and Discussion}

3.1. Optimization of One-Dimensional Chromatographic Conditions. One-dimensional chromatography was used to separate vitamin D from other impurities. We compared three different columns of Agilent Zorbax C8 $(4.6 \times 150 \mathrm{~mm}$, $3 \mu \mathrm{m})$, Welch ultimate ${ }^{\mathrm{R}} \mathrm{XB}-\mathrm{C} 30(4.6 \times 150 \mathrm{~mm}, 3 \mu \mathrm{m})$, and Daicel Corporation Chiralcel ${ }^{\mathrm{R}}$ OD-3R $(2.1 \mathrm{~mm} \times 150 \mathrm{~mm}$, $3 \mu \mathrm{m})$ and optimized the gradient elution procedure of mobile phases. The results showed that vitamin D and 
TABLE 1: The parameters of two-dimensional chromatography.

\begin{tabular}{lcc}
\hline & First dimension & Second dimension \\
\hline Flow rate & $0.4 \mathrm{~mL} / \mathrm{min}$ & $0.4 \mathrm{~mL} / \mathrm{min}$ \\
Mobile phase A & $\mathrm{H}_{2} \mathrm{O}$ & $\mathrm{ACN}: \mathrm{H}_{2} \mathrm{O}=95: 25$ \\
Mobile phase B & $\mathrm{MeOH}: \mathrm{ACN}=25: 75$ & $\mathrm{MeOH}$ \\
Autosampler & $50 \mu \mathrm{L}$ & \\
Column & Daicel chiralcel, OD-3R, $2.1 \mathrm{~mm} \times 150 \mathrm{~mm}, 3 \mu \mathrm{m}$ & Agilent ZORBAX Eclipse PAH, $4.6 \times 100 \mathrm{~mm}, 3.5 \mu \mathrm{m}$ \\
Column temperature & $35^{\circ} \mathrm{C}$ & $35^{\circ} \mathrm{C}$ \\
Detector & $\mathrm{UV} 264 \mathrm{~nm}$ & PDA $264 \mathrm{~nm}$ \\
& 0 to 15.3 minutes: Position $1-2$ (phase 1) \\
Valve & 15.3 to 17.2 minutes: Position $1-6$ (phase 2) \\
Capture column & 17.2 to 40 minutes: Position $1-2$ (phase 3) & Agilent ZORBAX Extend-C18, $4.6 \times 12.5 \mathrm{~mm}, 5 \mu \mathrm{m}$ \\
\hline
\end{tabular}

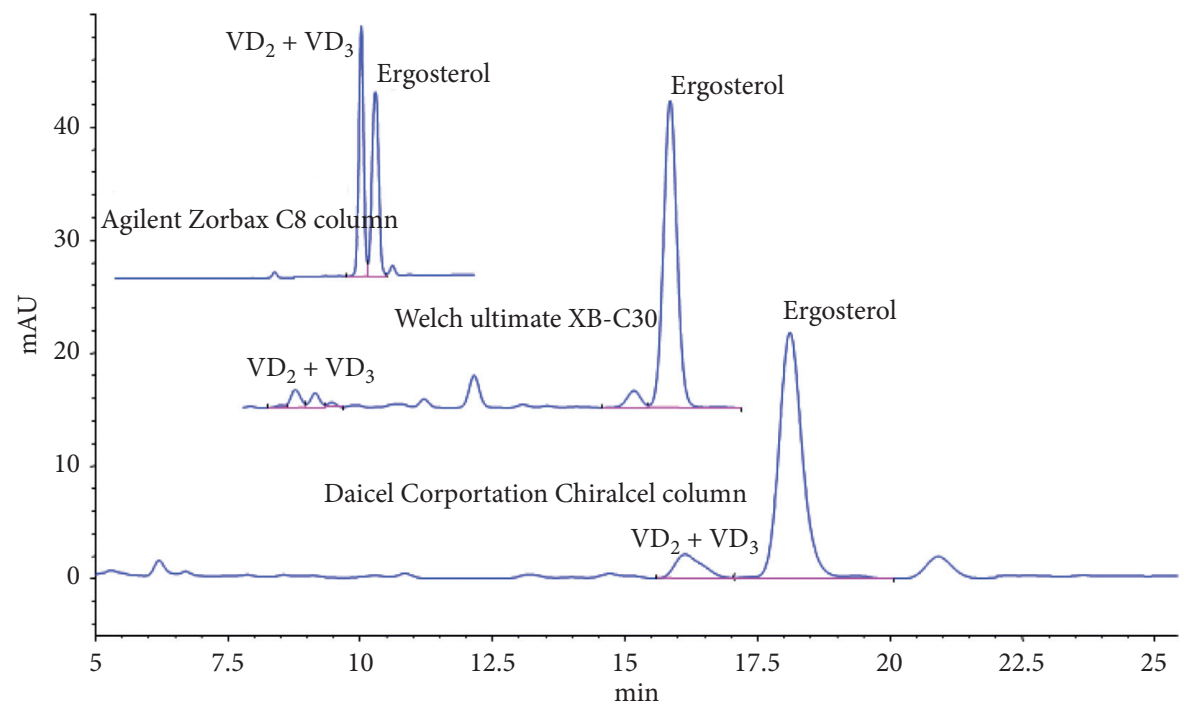

Figure 1: Separation of one-dimensional chromatogram by different columns in Lentinus edodes (spiking levels $100 \mu \mathrm{g} / 100 \mathrm{~g}$ for $\mathrm{VD}_{2}, \mathrm{VD}_{3}$, and ergosterol).

ergosterol could be separated by three chromatographic columns, but the methanol proportion in mobile phase reached $95 \%$ when vitamins $\mathrm{D}_{2}$ and $\mathrm{D}_{3}$ flowed out from Welch ultimate XB-C30 column and could not be retained on the C18 capture column. Actually, components in Lentinus edodes, such as phospholipid and fatty acid, can interfere with the analysis of vitamin D. As shown in Figure 1, the column of Daicel Corporation Chiralcel ${ }^{\mathrm{R}}$ OD-3R had a better separation than that of the Agilent Zorbax C8 column considering vitamin $\mathrm{D}$ and ergosterol.

\subsection{Configuration of Two-Dimensional Chromatographic} Flow Path and Valve Switching. After the primary separation was achieved on one-dimensional column, the elutions containing vitamins $\mathrm{D}_{2}$ and $\mathrm{D}_{3}$ were cut into a two-dimensional column for separation (see Figure 2 for the system connection mode). In order to completely transfer the elutions of vitamin $\mathrm{D}_{2}$ and $\mathrm{D}_{3}$ into the two-dimensional chromatography, the exact switching time of the switching valve must be determined. At the beginning of the experiment, the standard solution will be put into the one-dimensional chromatographic column to determine the peak time of vitamins $\mathrm{D}_{2}$ and $\mathrm{D}_{3}$ and the time of completely washing out the chromatographic column. Due to the influence of chromatographic system, solvent difference, and different chromatographic columns, the retention time of vitamins $\mathrm{D}_{2}$ and $\mathrm{D}_{3}$ in one-dimensional chromatographic separation will fluctuate slightly between each detection batch. Therefore, if the cutting time window is too narrow, it is easy to cause the loss of target substance which will result in deviation between batches. If the time window is too wide, the volume of solvent switching to two-dimensional separation column will be too large, which will produce solvent effect on two-dimensional separation. In this study, the fluctuation range of retention time was investigated by continuous injections. The final switching time window was (19.5-21.3 $\mathrm{min})$. The valve switching time and position are shown in Table 1.

3.3. Optimization of Two-Dimensional Chromatographic Conditions. In two-dimensional chromatography, the compatibility of mobile phase should be considered first. Therefore, reversed-phase chromatography is used in the separation of one-dimensional chromatography and two- 


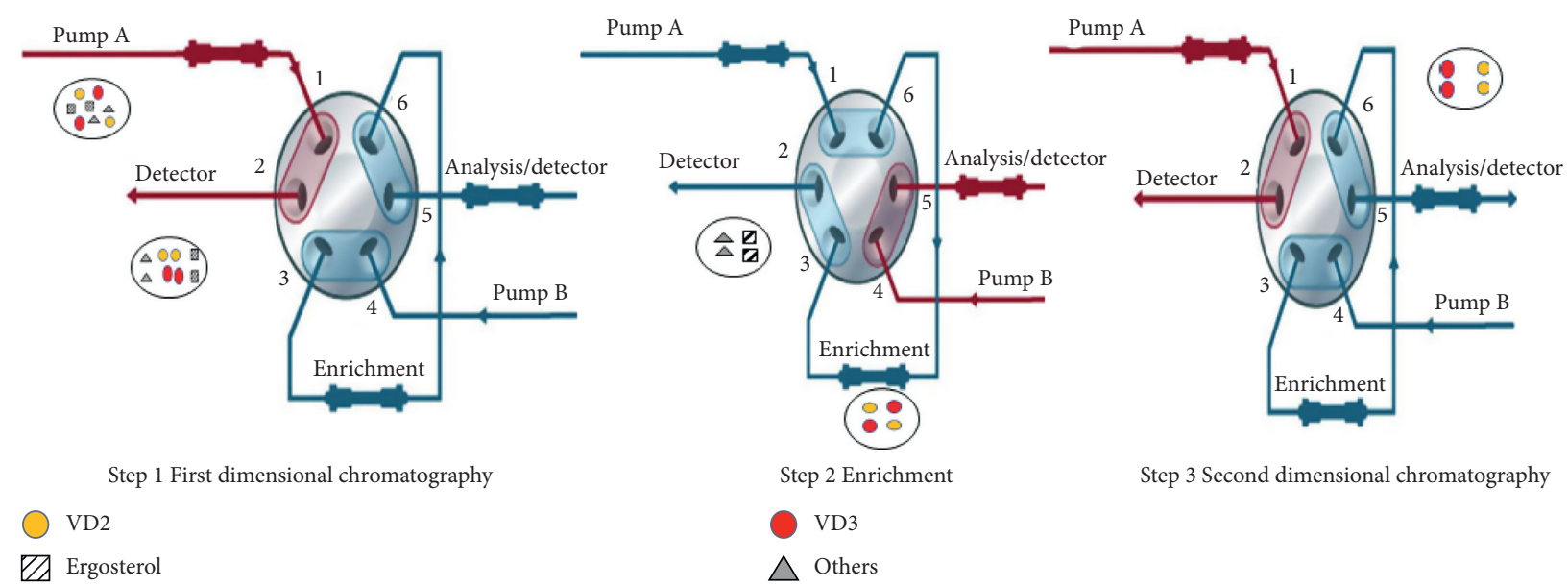

FIgURE 2: The diagram of system connection and the flow diagram of the analysis process.

dimensional chromatography. In the selection of mobile phase, methanol, acetonitrile, and water are commonly used solvents. In addition, the selection of chromatographic column is the key factor for the construction of reversedphase two-dimensional chromatography conditions. Agilent eclipse PAH $(4.6 \times 100 \mathrm{~mm}, 3.5 \mu \mathrm{m})$ is selected as the twodimensional chromatographic column, which forms a certain orthogonality relationship with the one-dimensional column (Daicel Corporation Chiralcel OD-3R, $2.1 \mathrm{~mm} \times 150 \mathrm{~mm}, 3 \mu \mathrm{m}$ ) and can improve the separation ability of the system. According to the separation results in Figure 3, when the ratio of acetonitrile (water content 5\%) to methanol was $95: 5$, separation of pre- $\mathrm{VD}_{2}, \mathrm{VD}_{2}$, pre- $\mathrm{VD}_{3}$, and $\mathrm{VD}_{3}$ was achieved on the two-dimensional column, and the peak symmetry was good, which fully met the quantitative requirements.

3.4. Optimization of Sample Saponification. In the process of vitamin $\mathrm{D}$ analysis in food, samples need to be saponified by potassium hydroxide ethanol solution. The commonly used saponification conditions are heating saponification and room temperature overnight saponification. In this study, homogeneous Lentinula edodes powder was selected as a typical sample to compare the effects of different saponification time on the determination results of vitamin $\mathrm{D}_{2}$ and $\mathrm{D}_{3}$ in Lentinus edodes. Results as shown in the Figure 4, the saponification condition of overnight saponification at room temperature $\left(25^{\circ} \mathrm{C}, 16\right.$ hours $)$ was chosen.

3.5. Selection and Optimization of Extraction Solvent. After saponification at $25^{\circ} \mathrm{C}$ for 16 hours, the determination results of vitamin $\mathrm{D}_{2}$ and $\mathrm{D}_{3}$ in Lentinus edodes were compared with different extraction solvents. As shown in Table 2, there was no significant difference in the determination results of $n$-hexane, ethyl acetate, hexane/ethyl acetate (4/6), and petroleum ether as extraction solvents $(P>0.05)$. The results of isooctane determination showed significant difference $(P<0.05)$, which was lower than that of the above solvents.
3.6. Method Validation. The standard series solutions with the concentrations of 50,100,200,400, 800, and $2000 \mathrm{ng} / \mathrm{mL}$ were prepared, and the standard curves were drawn according to the corresponding peak areas. The correlation coefficients were all greater than 0.999 , and the standard curves had good linearity. The limit of quantitation (LOQ) was investigated according to 10 times of the signal-to-noise ratio. When $5 \mathrm{~g}$ of wet sample was taken for determination, the limit of quantitation was $0.025 \mu \mathrm{g} / 100 \mathrm{~g}$.

The homogenized Lentinula edodes powder was selected as the sample and was saponified at $25^{\circ} \mathrm{C}$ for 16 hours and extracted with $n$-hexane/ethyl acetate $=4 / 6$. Each standard addition concentration was determined 6 times in parallel. The results are shown in Table 3. The recoveries of $\mathrm{VD}_{2}$ and $\mathrm{VD}_{3}$ were $80.4-93.6 \%$ and $82.3-92.0 \%$, respectively. The RSD of six repeated determinations was all less than $5 \%$.

3.7. Application of Developed Method. We collected 9 kinds of edible fungus from supermarkets in Hangzhou, China. Each species was collected from three different supermarkets with a sampling volume of $1.0 \mathrm{~kg}$. After the samples were separated by the quartering method, the edible fungi of the same species were made into mixed samples and then packed separately for testing. The contents of vitamin $\mathrm{D}_{2}$ and $\mathrm{D}_{3}$ in 9 edible fungi were determined by this method and liquid chromatography tandem mass spectrometry, respectively, as described by Cantorna et al. [4]. Vitamin $\mathrm{D}_{3}$ was not detected in 9 kinds of edible fungi, and the content of vitamin $\mathrm{D}_{2}$ ranged from $0.11 \mu \mathrm{g} / 100 \mathrm{~g}$ to $123 \mu \mathrm{g} / 100 \mathrm{~g}$ (Table 4). The content of vitamin $\mathrm{D}_{2}$ in dried mushroom was the highest, while that in fresh mushroom was the lowest. The limit of quantification (LOQ) in fresh mushroom was $0.025 \mu \mathrm{g} / 100 \mathrm{~g}$. There was no significant difference between this method and LC-MS/MS $(P>0.05)$. Usually, compounds of vitamin $\mathrm{D}$ were analyzed by common one-dimensional liquid chromatography [14]. However, the separation of targeted analytes might be disturbed by complex sample matrix. Two-dimensional liquid chromatography is a good choice for analyzers due to its strong peak capacity. 


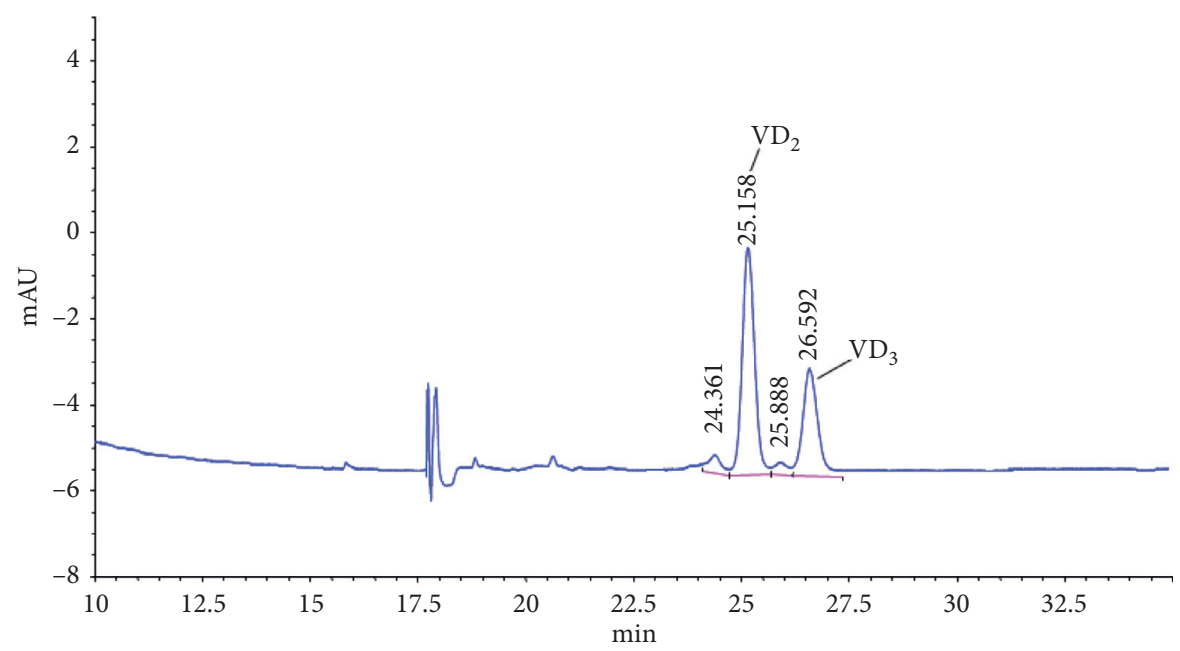

FIgURE 3: Separation of two-dimensional chromatogram of vitamins $\mathrm{D}_{2}$ and $\mathrm{D}_{3}$ in Lentinus edodes (spiking levels $100 \mu \mathrm{g} / 100 \mathrm{~g}$ for $\mathrm{VD}$ and $\left.\mathrm{VD}_{3}\right)$.

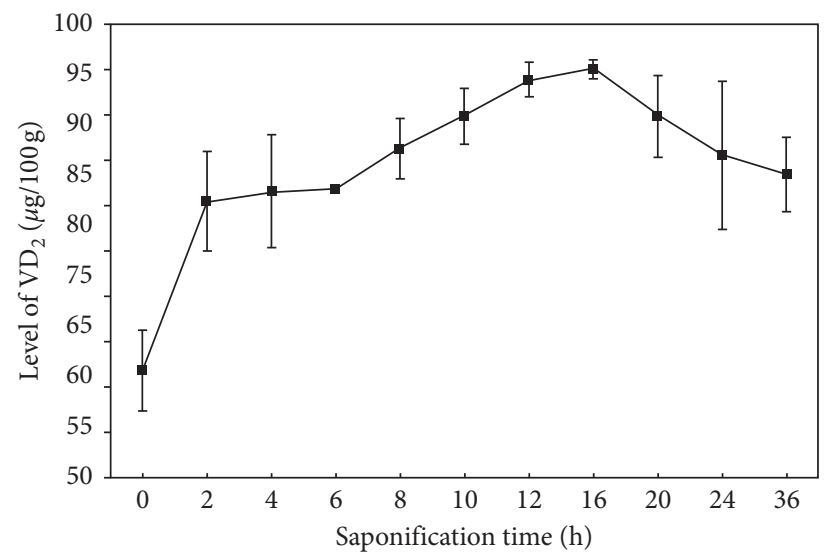

FIGURE 4: Levels of $\mathrm{VD}_{2}$ with different saponification time $(\mu \mathrm{g} / 100 \mathrm{~g})$.

TABLE 2: Obtained results with different extraction solvents $(n=6)$.

\begin{tabular}{lccccc}
\hline \multicolumn{4}{c}{ Vitamin content after extraction by different solvents $( \pm \mathrm{SD}, \mu \mathrm{g} / 100 \mathrm{~g})$} \\
& $n$-Hexane/ethyl acetate $(4 / 6)$ & $n$-Hexane & Ethyl acetate & Isooctane & Petroleum ether \\
\hline $\mathrm{VD}_{2}$ & $85.2 \pm 2.6$ & $86.6 \pm 4.8$ & $86.7 \pm 2.4$ & $77.2 \pm 4.5$ & $85.7 \pm 4.9$ \\
$\mathrm{VD}_{3}$ & $88.2 \pm 4.1$ & $87.1 \pm 4.4$ & $90.1 \pm 5.2$ & $89.1 \pm 3.9$ & $89.2 \pm 4.5$ \\
\hline
\end{tabular}

Note: $\mathrm{VD}_{3}$ was spiked into sample with a level of $100 \mu \mathrm{g} / 100 \mathrm{~g}$.

TABLE 3: Recovery of Lentinula edodes powder with different spiking levels $(n=6)$.

\begin{tabular}{cccccc}
\hline & & Sample & \multicolumn{3}{c}{$\begin{array}{c}\text { Spiking level } \\
(\mu \mathrm{g} / 100 \mathrm{~g})\end{array}$} \\
& matrix & 50 & 100 & 200 \\
\hline \multirow{3}{*}{$\mathrm{VD}_{2}$} & Level $(\mu \mathrm{g} / 100 \mathrm{~g})$ & 95.0 & 138.0 & 184.2 & 270.5 \\
& $\mathrm{RSD}(\%)$ & 0.74 & 2.03 & 2.50 & 3.55 \\
& Recovery (\%) & - & 86.0 & 89.2 & 87.7 \\
\hline & Level $(\mu \mathrm{g} / 100 \mathrm{~g})$ & Not detected & 43.1 & 89.8 & 173.7 \\
$\mathrm{VD}_{3}$ & RSD (\%) & - & 4.64 & 2.45 & 2.42 \\
& Recovery (\%) & - & 86.3 & 89.8 & 86.9 \\
\hline
\end{tabular}

TABLE 4: The levels of $\mathrm{VD}_{2}$ in 9 edible fungi.

\begin{tabular}{lcc}
\hline \multirow{2}{*}{ Sample } & \multicolumn{2}{c}{ Level of $\mathrm{VD}_{2}(\mu \mathrm{g} / 100 \mathrm{~g})$} \\
& 2D-HPLC & LC-MS/MS \\
\hline Baeospora myosura & 35.2 & 36.3 \\
Colored Lentinus edoes & 123.4 & 119.8 \\
Auricularia auricula & 64.3 & 65.7 \\
Flammulina velutipes & 0.14 & 0.16 \\
Pleurotus ostreatus & 0.11 & 0.13 \\
Cordyceps sinensis flower & 0.51 & 0.49 \\
Dictyophora & 21 & 25 \\
Agrocybe chaxingu & 1.45 & 1.39 \\
Pleurotus eryngii & 0.53 & 0.57 \\
\hline
\end{tabular}




\section{Conclusion}

A method for the determination of vitamin $D_{2}$ and $D_{3}$ in edible fungi by reverse phase-two dimensional liquid chromatography was established. The method is simple, sensitive, accurate, and precise, and the limit of quantification can meet the requirements for the determination of vitamin $\mathrm{D}$ in selected fresh mushrooms.

\section{Data Availability}

The data used to support the findings of this study are included within the article.

\section{Conflicts of Interest}

The authors declare that they have no conflicts of interest.

\section{References}

[1] T. Higashi, K. Shimada, and T. Toyo'oka, “Advances in determination of vitamin D related compounds in biological samples using liquid chromatography-mass spectrometry: A review," Journal of Chromatography B, vol. 878, no. 20, pp. 1654-1661, 2010.

[2] G. F. Combs and J. P. McClung, The Vitamins: Fundamental Aspects in Nutrition and Health, American Academic Press, Salt Lake, UT, USA, 5th edition, 2017.

[3] K. Edvardsen, M. B. Veierød, M. Brustad, T. Braaten, O. Engelsen, and E. Lund, "Vitamin D-effective solar UV radiation, dietary vitamin D and breast cancer risk," International Journal of Cancer, vol. 128, no. 6, pp. 1425-1433, 2011.

[4] M. T. Cantorna and B. D. Mahon, "Mounting evidence for vitamin $\mathrm{D}$ as an environmental factor affecting autoimmune disease prevalence," Experimental Biology and Medicine, vol. 229, no. 11, pp. 1136-1142, 2005.

[5] ISO 14892:2002(E)/IDF 177:2002(E), Dried skimmed milkDetermination of vitamin D content using high-performance liquid chromatography.

[6] GB 5009.82-2016, Determination of Vitamin A, D, E in Foods, Chinese National Standards, Beijing, China, 2017.

[7] BS EN 12821: 2009, Foodstuffs-Determination of Vitamin D by High Performance Liquid Chromatography-Measurement of Cholecalciferol (D3) or Ergocalciferol (D2), European Union, Brussels, Belgium, 2009.

[8] Official methods of analysis of AOAC International, Official Method 981.17, AOAC International, Gaithersburg, MD, USA, 2006.

[9] P. Mattila, K. Karoliina, M. Eurola et al., "Contents of vitamins, mineral elements, and some phenolic compounds in ultivated mushrooms," Jounal of Agricultural and Food Chemistry, vol. 49, no. 5, pp. 2343-2348, 2001.

[10] K. Takamura, H. Hoshino, T. Sugahara, and H. Amano, "Determination of vitamin $\mathrm{D}_{2}$ in shiitake mushroom (lentinus edodes) by high-performance liquid chromatography," Journal of Chromatography A, vol. 545, no. 1, pp. 201-204, 1991.

[11] V. J. Jasinghe and C. O. Perera, "Distribution of ergosterol in different tissues of mushrooms and its effect on the conversion of ergosterol to vitamin $\mathrm{D}_{2}$ by UV irradiation," Food Chemistry, vol. 92, no. 3, pp. 541-546, 2005.

[12] J. A. Ko, B. H. Lee, J. S. Lee, and H. J. Park, "Effect of UV-B exposure on the concentration of vitamin $\mathrm{D}_{2}$ in sliced shiitake mushroom (lentinus edodes) and white button mushroom (Agaricus bisporus)," Journal of Agricultural and Food Chemistry, vol. 56, no. 10, pp. 3671-3674, 2008.

[13] T. S. Keflie, N. Nölle, C. Lambert, D. Nohr, and H. Konrad Biesalski, "Impact of the natural resource of UVB on the content of vitamin $\mathrm{D}_{2}$ in oyster mushroom (Pleurotus ostreatus) under subtropical settings," Saudi Journal of Biological Sciences, vol. 26, no. 7, pp. 1724-1730, 2019.

[14] K. M. Phillips, D. M. Ruggio, R. L. Horst et al., "Vitamin D and sterol composition of 10 types of mushrooms from retail suppliers in the United States," Jounal of Agricultural and Food Chemistry, vol. 59, no. 14, pp. 7841-7853, 2010.

[15] K. M. Phillips, W. Craig Byrdwell, J. Exler et al., "Development and validation of control materials for the measurement of vitamin $\mathrm{D}_{3}$ in selected US foods," Journal of Food Composition and Analysis, vol. 21, no. 7, pp. 527-534, 2008.

[16] G. A. Abernethy, "A rapid analytical method for cholecalciferol (vitamin $\mathrm{D}_{3}$ ) in fortified infant formula, milk and milk powder using Diels-Alder derivatisation and liquid chromatography-tandem mass spectrometric detection," Analytical and Bioanalytical Chemistry, vol. 403, no. 5, pp. 1433-1440, 2012.

[17] ISO 20636:2018(E), Infant formulas and adult nutritionalsDetermination of vitamin D by liquid chromatography-mass spectrometry.

[18] AOAC Official Method, Vitamin D in Infant Formula and Adult/Pediatric Nutritional Formula Ultra-high-performance Liquid Chromatography/Tandem Mass Spectrometry, AOAC, Gaithersburg, MD, USA, 2011.

[19] AOAC Official Method, 5 Analysis of Vitamin D2 and Vitamin D3 in Fortified Milk Powders, Infant Formulas, and Adult/Pediatric Nutritional Formulas Liquid Chromatography-Tandem Mass Spectrometry, AOAC, Gaithersburg, MD, USA, 2016.

[20] B. Huang, K. Xing, F. Zheng et al., "Simultaneous determination of vitamin $\mathrm{D}_{2}$ and $\mathrm{D}_{3}$ in infant formula by SPE-UPLC/ MS," Chinese Journal of Health Laboratory Technology, vol. 24, no. 22, pp. 3203-3207, 2014.

[21] S. Rao Koyyalamudi, S. c. Jeong, C. h Song et al., "Vitamin $\mathrm{D}_{2}$ formation and bioavailability from Agaricus bisporus button mushrooms reated with ultraviolet irradiation," Jounal of Agricultural and Food Chemistry, vol. 57, no. 8, pp. 3351-3355, 2009.

[22] S. R. Koyyalamudi, S.-C. Jeong, G. Pang, A. Teal, and T. Biggs, "Concentration of vitamin $\mathrm{D}_{2}$ in white button mushrooms (Agaricus bisporus) exposed to pulsed UV light," Journal of Food Composition and Analysis, vol. 24, no. 7, pp. 976-979, 2011.

[23] Y. Zhang, Y. Shen, Y. Li et al., "Quantitative determination of vitamin $\mathrm{D}_{2}$ in edible mushrooms using UPLC-MS/MS," Journal of Edible Fungi, vol. 26, no. 1, pp. 48-54, 2019.

[24] L. Qi, L. Yan, L. Zhang et al., "Two-dimensional liquid chromatography method for the conten determination of VA, $\mathrm{VD}_{3}$, VE in functional food," Chinese Journal of Health Laboratory Technology, vol. 25, no. 3, pp. 340-343, 2015.

[25] Y. Zhang, D. Zhang, Y. Cao et al., "Simultaneous determination of Vitamins A, D in Vitamin A and D pharmaceutical by online two-dimensional reverse-phase liquid chromatography, FENXI CESHI XUEBAO," Journal of Instrumental Analysis, vol. 35, no. 1, pp. 28-34, 2016.

[26] J. Cen, S. Ou, L. Zhou et al., "Simultaneous determination of vitamin $\mathrm{A}, \alpha$-tocopherol and vitamin $\mathrm{D}_{3}$ in in-fant milk powder with two-dimensional high performance liquid chromatography," China Dairy Industry, vol. 45, no. 2, pp. 43-46, 2017. 